Vol. 2 No. 2 Juli 2019

ISSN 2614-2775

e-ISSN 2621-8143
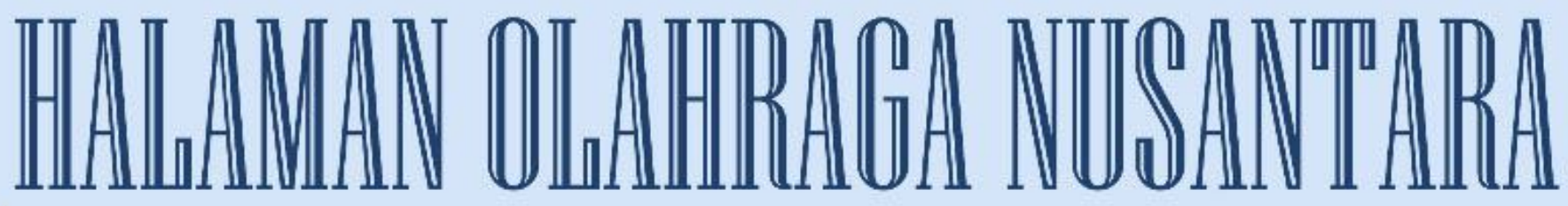

Surnal @lmu Xeolahragaan

Diterbitkan Oleh:

Program Studi Pendidikan Olahraga

Fakultas Keguruan dan Ilmu Pendidikan

Universitas PGRI Palembang

\begin{tabular}{|c|c|c|c|c|c|}
\hline Jurnal & Volume & Nomor & Halaman & Palembang & ISSN/e-ISSN \\
\hline IIalaman Oahrayg Ninsantarata & 2 & 2 & $97-197$ & 2019 & $\begin{array}{c}2614-2775 / \\
2621-8143\end{array}$ \\
\hline
\end{tabular}


Halaman Olahraga Nusantara (Jurnal Ilmu Keolahragaan)

P-ISSN 2614-2775

Volume 2, No. 2, Januari 2019

E-ISSN 2621-8143

\section{DAFTAR ISI}

Hasil Penelitian

Halaman

Penerapan Model Permainan Rounders Yang Dimodifikasi Terhadap Kemampuan Gerak Dasar Murid Sd Negeri Paccinongan Kabupaten Gowa

- Benny B, M.Rachmat Kasmad

Pelaksanaan Kegiatan Belajar Mengajar Pendidikan Jasmani di Sekolah Dasar Inklusi

- Bambang Gatot Sugiarto

Pengaruh Metode Latihan Terhadap Daya Tahan Fisik Siswa Ekstrakurikuler Sepak Bola Sma N 2 Tanjung Raja

- Mutiara Fajar.

Survei Minat Member Yang Mengikuti Fitness Pada Pusat Kebugaran Kota Palembang

- Hengki Kumbara.

Peningkatan Pengaruh Latihan Kelincahan Terhadap Kemampuan Menggiring Bola Pada Siswa Sma Negeri 3 Samarinda

- Ruslan, Nurjamal

Penerapan Permainan Dengnan Media Swiss Ball Untuk Meningkatkan Kelentukan Lower Back (Pada Mahasiswa Kop Aerobic Gymnastics Universitas Negeri Jakarta)

- M Dian Susanto, Sri Nuraini $141-153$

Patrol Multiguna Sebagai Alternatif Media Pembelajaran Tolak Peluru Di Smp Negeri 1 Sei Balai Kabupaten Batu Bara Tahun Ajaran 2017/2018

- Joko Priono $154-166$ 
Kecerdasan Gerak Dalam Pendidikan Jasmani

- Hilda Oktriyeni....................................................................... 167-176

Analisis Kesalahan Tendangan Atlet Pencak Silat Universitas PGRI Palembang

- Bayu Iswana............................................................................ 177-185

Pengaruh Metode Pembelajaran Dan Kriteria Layanan Bantuan:

Meningkatkan Gerak Dasar Lompat Jauh Gaya Jongkok Siswa Tunagrahita Ringan Pada Pembelajaran Penjasorkes SLB PKK Bandar Lampung

- Rachmi Marsheilla Aguss.............................................................. 186-197 


\title{
PENERAPAN PERMAINAN DENGNAN MEDIA SWISS BALL UNTUK MENINGKATKAN KELENTUKAN LOWER BACK (PADA MAHASISWA KOP AEROBIC GYMNASTICS UNIVERSITAS NEGERI JAKARTA)
}

\author{
Oleh: M Dian Susanto, Sri Nuraini \\ (Dosen Universitas Negeri Jakarta)
}

\begin{abstract}
Abstrak
Penelitian ini bertujuan untuk meningkatkan punggung bawah melalui permainan bola swiss pada siswa polisi pada senam aerobik, Universitas Negeri Jakarta. Metode penelitian yang digunakan dalam penelitian ini adalah melakukan penelitian (Action Research), mahasiswa senam aerobik di Universitas Jakarta. senam aerobik, Universitas Negeri Jakarta. Indikatornya adalah: sikap awal, sikap, sikap akhir. Hasil penelitian dari 20 siswa perempuan, hasil tes pertama dilakukan sebagai siklus pertama, kemudian hasil dari siklus data pertama sebagai referensi di siklus kedua. Dan untuk siswa yang mengikuti tes awal untuk 20. Ada 9 siswa yang dinyatakan berhasil meningkat 18 siswa atau 90\%. Sehingga ada tingkat determinasi yang lebih rendah untuk mahasiswa senam aerobik, Universitas Negeri Jakarta.
\end{abstract}

Kata kunci : Permainan dengan media swiss ball, kelentukan lower back.

\section{MEDIA FOR THE IMPLEMENTATION OF GAMES WITH SWISS BALL MEDIA TO IMPROVE RESISTANCE (IN KOP AEROB STUDENTS, JAKARTA GYMNASTICS, STATE UNIVERSITY)}

\begin{abstract}
This study aims to raise the lower back through a swiss ball game on kop students on aerobic gymnastics, Jakarta State University. The subjects of this study were 20 students of aerobic gymnastics at the State University of Jakarta.The research method used in this study is action research (Action Research), namely by giving special treatment to female students to improve lower back flexibility on kop students of aerobic gymnastics, Jakarta State University. The indicators measured in this study are: initial attitude, attitude, final attitude.Based on the results of research from 20 female students, the results of the initial tests were carried out as reference data in the first cycle, then the results of the first cycle data as a reference in the second cycle. And for the number of students who took the initial test amounted to 20. For the results of success in the first cycle there were 9 students who were declared successful in increasing or $65 \%$, and in the second cycle students who were declared successful increased by 18 students or $90 \%$. So that it can be concluded that the application of the game with Swiss Ball media can increase the lower back determination of Kop students in aerobic gymnastics, Jakarta State University. Keywords: Games with Swiss ball media, specify lower back.
\end{abstract}




\section{A. PENDAHULUAN}

Olahraga merupakan suatu bentuk aktivitas fisik yang terencana dan terstruktur yang melibatkan gerakan tubuh berulang-ulang dan ditunjukan untuk meningkatkan kebugaran jasmani. Peranan olahraga bagi tubuh kita juga sangat banyak tentang bagaimana fungsi dan cara kerja organ-organ tubuh dalam melakukan suatu kegiatan yang melibatkan jatung, paru, otot, syaraf, pembuluh darah, otot kelenjar, dan sebagainya. Serta perubahan-perubahan dari dalam maupun dari luar tubuh yang bersifat sementara maupun yang bersifat menetap karena melakukan olahraga baik untuk kesehatan maupun untuk tujuan prestasi. Olahraga sudah menjadi kebutuhan bagi semua orang, baik itu laki-laki, perempuan, orang tua, dan bahkan anak kecil sekalipun.

Sudah banyaknya fasilitas olahraga yang tersedia memudahkan kita semua untuk berolahraga tidak hanya di sekolah, ditempat lain pun seperti taman bermain, taman kota hingga pusat-pusat kebugaran menyajikan berbagai macam fasilitas untuk berolahraga. Semakin berkembangnya kesadaran masyarakat untuk menanamkan pola hidup sehat membuat aktivitas olahraga semakin meningkat. Manfaat yang di dapatkan, selain menjadikan tubuh kita sehat bugar dan tak hanya fisik secara keseluruhan yang mendapatkan manfaat dari olahraga, karena setiap organ-organ tubuh juga mendapatkan manfaat olahraga seperti peningkatan otot, tulang lebih kuat, sendi sehat, dan jantung lebih sehat. sehingga dapat melakukan aktivitas yang berat secara terus menerus dalam waktu yang relatif lama.

Selain untuk kebugaran, olahraga mempunyai banyak manfaat lainnya, seperti untuk rehabilitasi, rekreasi dan prestasi. Dalam olahraga juga ada beberapa pilar olahraga diantaranya yaitu olahraga pendidikan, olahrga prestasi dan olahrga rekreasi. Olahraga pendidikan yaitu pendidikan jasmani dan olahraga yang dilaksanakan sebagai proses pendidikan yang teratur dan bekelanjutan untuk memperoleh pengetahuan, kepribadian, keterampilan, kesehatan, dan kebugaran jasmani. Lalu olahraga prestasi dimana olahraga yang membina dan mengembangkan olahragawan secara terencana, berjenjang, dan berkelanjutan melalui kompetisi untuk mencapai 
prestasi. Sedangkan olagrag rekreasi yaitu olahraga yang mengarah kepada aktivitas gerak yang bertujuan untuk kesenangan dan kegembiraan.

Jenis-jenis olahraga yang bisa dilakukan, pertama olahraga permainan, seperti bola voli, sepak bola, sepak takraw, basket, futsal, tenis meja, bulutangkis. kedua olahraga terukur seperti atletik, renang, balap sepeda, ketiga olahraga tidak terukur seperti senam, renang indah, loncat indah dan yang keempat olahraga bela diri seperti taekwondo, gulat, karate, silat, judo, kempo, tinju dan wushu. Empat jenis olahraga yang sudah disebutkan bisa juga mempengaruhi psikologi seseorang seperti konsentrasi dan stres. Konsentrasi salah satu faktor yang sangat penting dalam olahraga. contohnya dalam sebuah pertandingan konsentrasi adalah kemampuan olahragawan dalam pemusatan perhatian pemikiran terhadap sesuatu usaha setelah adanya kesiapan dan kematangan. Kemudian stres juga merupakan salah satu faktor yang sangat berpengaruh dalam olahraga biasanya stres akan dirasakan ketika seorang olahragawan sedang menghadapi tekanan yang sangat tinggi contohnya pada saat olahragawan tersebut akan melakukan sebuah pertandingan, karena dalam sebuah pertandingan akan ada beberapa faktor tekanan yang luar biasa bisa dari diri sendiri, penonton ataupun dari pihak lawan.

Kemudian Stres contohnya dalam olahraga tidak terukur pada cabang olahraga senam merupakan faktor yang sangat penting karena olahraga senam membutuhkan konsentrasi tinggi dan kesempurnaan gerak. Cabang olahraga senam merupakan olahraga yang melibatkan performa tubuh seperti kekuatan, kecepatan dan keserasian gerak fisik yang teratur. Apabila tingkat stres dalam cabang olahraga itu tinggi maka dari berbagai rangkaian gerak tersebut akan mengakibatkan hilangnya konsentrasi dalam melakukan rangkaian koreografi sangat kompleks dengan tingkat kesulitan yang sudah baku serta keselarasan gerak dengan irama musik dan waktu yg sudah ditetapkan, pada cabang olahraga senam tersebut, senam yang di maksud pada pembahasan kali ini adalah senam aerobic gymnastics.

Aerobic gymnastics adalah suatu kemampuan untuk menampilkan gerakan kompleks dengan intensitas tinggi dimana dilakukan sesuai dengan musik yang 
berasal dari latihan aerobik tradisional, penampilan harus menunjukan gerakan yang terus-menerus dengan memperlihatkan kelenturan, kekuatan, serta penggunaan seven basic step atau tujuh langkah dasar dengan difficulty element atau tingkat kesulitan yang sempurna.

Dalam pertandingannya secara garis besar penilaian dalam Aerobic Gymnastics terdiri dari 3 faktor yaitu artistic, execution, dan difficulty, Artistic berarti kemampuan atlet untuk menampilkan koreografi yang sempurna dengan mempertunjukkan penampilan yang indah. Execution berarti kesempurnaan dalam melakukan teknik gerak agar tidak mendapat potongan atau pengurangan. Dan yang ketiga adalah difficulty elements ( tingkat kesulitan) adalah tingkat kesulitan gerak. Kemudian Pada pertandingan Aerobic Gymnasticsdua nomor pertandingan yaitu Age Group dan senior . Pada nomor Age Group terdapat tiga kategori yaitu National Development (9-11 tahun), Age Group 1 (12-14 tahun), Age Group 2 (15-17 tahun). Adapun difficultyelement atau tingkat kesulitan yang wajib dilakukan dalam setiap kategorinya berbeda-beda. Pada kategori National Development ada 4 difficulty element atau tingkat kesulitan yang wajib diambil yaitu Grup A (dynamic strength) : push up, Grup B (static strength) straddle support, Grup C (jump and leaps) : air turn, Grup D (flexibility and balance) : split through

Pada penulisan ini penulis ingin membahas mengenai Kelentukan dimana kelentukan merupakan hal yang sangat penting untuk menunjang gerak seperti saat akan melakukan difficulty element atau tingkat kesulita pada cabang olahraga senam aerobic gymnastics, kelentukan merupakan salah satu penunjang kesempurnaan gerak dan keseimbangan penampilan yang dimana tergolong dalam Grup D (flexibility and balance). Mengingat pentingnya difficulty element ini pada kategori National Development peneliti berupaya memecahkan masalah yang ada pada mahasiswa aerobic gymnastics Univeritas Negeri Jakarta masih bermasalah saat melakukan gerak difficulty element atau tingkat kesulitan dalam Grup D dimana harus mempunyai kelentukan yang baik pada saat melakukan gerakannya. Salah satunya 
otot lower back untuk menujang kesempurnaan grak dan keseimbanagan saat melakukan diffecilty element Grup D.

Maka dari sinilah dibutuhan latiahn-latihan yang menunjang untuk memperbaiki kelentukan lower back pada mahasiswaa.Sekarang dalam melakukan aktivitas latihan tidak hanya menggunakan model latihan yang biasa saja, karena itu juga bisa berdampak kejenuhan pada atlit itu sendiri. Contohnya bisa menggunakan model-model latihan dengan cara yang ber variatif misalnya menggunakann permaina-permainan untuk melatih apa yang ingin di targetan seorang pelatih pada atletnya, permaina-permaina bisa juga digunakan sebagai metode untuk menujang seperti kelincahan, kelentukan, kecepatan dan power. Maka dari itu penulisan ingin membahas mengenai permainan swiss ball untuk melatih kelentukan lower back.

Mengingat kelenturan adalah hal yang harus sering dilatih oleh mahasiswa kop aerobic gymnastics sehingga akan memudahkan untuk menguasai teknik gerakan-gerakan yang membutuhkan kelentukan. Disini penulisan menemukan masalah yang terjadi dilapangan, yaitu mahasiswa kop aerobic gymnastics membutuhkan beberapa latihan untuk melatih kelentukan, latihan seperti ini juga memberikan hal baru dalam berlatih. Mengingat pentingnya kelentukan pada atlit aerobic gymnastics peneliti berupaya untuk memecahkan masalah yang ada. Masalah yang di pecahkan dalam penelitian ini memberikan solusi terbaik agar atlit memiliki tingkat kelentukan yang baik. Salah satu solusinya dapat dilakukan dengan menggunakan permainan dengan media swiss ball sehingga diharapkan pada akhirnya dapat melakukan kelentukan dengan baik saat melakukan teknik gerakan-gerakan aerobics gymnastics.

\section{B. METODOLOGI PENELITAN}

Dalam penelitian ini, teknik pengumpulan data yang digunakan adalah teknik pengamatan dan observasi untuk data kualitatif, serta hasil penelitian berupa evaluasi formatif (teknik penilaian) yang dilakukan oleh peneliti dan kolabor sebagai data kuantitatif, yang dijadikan responden dalam satu teknik 
Teknik yang dikumpulkan dalam menganalisis data yang terkumpul dilakukan dengan mencari sumber data dalam penelitian yaitu mahasiswa kop aerobic gymnastic dan pelatih dalam jenis data kuantitatif yang diperoleh langsung dari observasi dan pengamatan yang dilakukan kolaborator sebelum dan sesudah tindakan berupa proses meningkatkan kelentukan melalui permainanpermainan.

Kelentukan adalah kemampuan sendi untuk melakukan gerakan dalam ruang gerak sendi secara maksimal" ". Orang yang memiliki kelentukan yang baik adalah orang yang memiliki ruang gerak yang luas dalam sendi-sendinya dan mempunyai otot yang elastis.

Jadi dapat disimpulkan bahwa kelentukan adalah kemampuan untuk melakukan gerakan dalam ruang gerak sendi yang seluas-luasnya artinya semakin luas gerak sendi melakukan gerakan maka semakin bagus pula kelentukan yang dimiliki.

a) Jenis Instrumen

Dalam penelitian ini jenis tes menggunakan Trunk Ekstension dan alat yangdigunakan adalah sebagai berikut :

1. Daftar absensi dan alat tulis

2. Kertas pencatat dan pulpen

3. Alat pengukur kelentukan (penggaris)

\section{Tujuan}

Tujuan dari tes ini adalah untuk mengukur kelenturan lower back pada seorang mahasiwa/atlet.

\section{Peralatan yang dibutuhkan}
a. Matras dan penggaris (Trunk Ekstension)
b. Seorang asisten.

\section{Prosedur pelaksanaan}


Posisi awal:

a. berbaring tengkurap di lantai dengan tangan tergenggam di sisi haed

b. Kaki lurus tanpa ada yang terangkat

\section{Pergerakan}

a. Tidur tengkurap dengan kedua tangan saling menggapit di belakang kepala

b. Naikkan kepala setinggi mungkin sambil menjaga pinggul agar tidak menyentuh tanah

c. Seorang asisten menahan kaki

d. Catat jarak vertikal, hingga 1/4 inci terdekat, dari ujung hidung ke tanah

e. Ulangi tes 3 kali dan catat jarak terbaik

\section{Validitas}

Ada suatu tabel yang dapat membandingkan kelentukan dengan tingkat kebugaran jasmani memiliki korelasi yang tinggi ${ }^{2}$.

Indikator keberhasilan dari penelitian ini ditentukan oleh :

1. Meningkatnya kelentukan pada mahasiswa kop aerobic gymnastics dengan permainan swiss ball

2. Mencapai hasil yang diinginkan, yaitu $80 \%$ kelentukan mahasiswa kop aerobic gymnastics

Tabel 1 Nilai skor Trunk Ekstension

\begin{tabular}{|l|l|l|}
\hline Keterangan & Laki-laki & Perempuan \\
\hline Baik sekali & $>10.00$ & $>9.75$ \\
\hline Baik & $10.00-8,00$ & $9.75-7.75$ \\
\hline Sedang & $7.99-6.00$ & $7.74-5.75$ \\
\hline Kurang & $5.99-3.00$ & $5.74-2.00$ \\
\hline Kurang sekali & $3.00<$ & $2.00<$ \\
\hline
\end{tabular}


Skor penilaian Trunk Ekstension mahasiswa kop aerobic gymnastic didapatkan dari data yang peneliti hitung sendiri dengan cara:

1. Mengambil data awal kelentukan pada mahasiswa kop aerobic gymnasticUniversitas Negeri Jakarta.

2. Setelah data terkumpul peneliti mencari nilai rata-rata

3. Menghitung dengan rumus (lampiran)

4. Mendapatkan hasil dari penilaian Trunk Ekstension mahasiswa kop aerobic gymnastics.

3. Validasi Instrumen

Dalam validasi instrumen ini peneliti menggunakan 3 ahli masing-masing dari, Dosen permaiana Hartman Nugraha M.Pd, Dosen tes pengukuran olahraga Muhammad Arif, M.Pd dan Pelatih Aerobic Gymnastics Eko Wibby Julianto, S.Pd.

\section{HASIL PENELITIAN DAN PEMBAHASAN}

Penelitian ini diawali dengan pengambilan biodata dan diadakan tes awal pada tanggal 18 januari 2019. Pelaksanaan kegiatan tes awal yang dilakukan peneliti kepada mahasiswa kop aerobic gymnastics Universitas Negeri jakarta yang berjumlah 20 orang, yang terdiri dari 6 mahasiswa laki-laki dan 14 mahasiswa perempuan. Kegiatan tes awal ini dilaksanakan menggunakan alat trunk ekstention guna untuk mengidentifikasi kondisi awal kemampuan mahasiswa terhadap kelentukan lower back pada mahasiswa kop aerobic gymnastics universitas negeri Jakarta.

Dalam pertemuan ini mahasiswa lebih diutamakan pengenalan terhadap apa yang akan dilakukan yaitu tentang pengertian kelentukan, manfaat kelentukan pada cabang olahraga aerobic gymnastics, dan cara meningkatkan kelentukan melalui permainan-permainan. Pembelajaran diadakan di kampus b universitas negeri Jakarta tempat kop aerobic gymnastics universitas negeri Jakarta melakukan sesi latihan.

Dari hasil tes awal trunk estension dari 20 mahasiswa data sebagai acuan siklus I dan kemudian hasil tes siklus I sebagai acuan untuk siklus II. Pada siklus I 
mahasiswa yang dinyatakan berhasil sejumlah 9 mahasiswa (45\%), 11 mahasiswa dinyatakan belum berhasil, dan pada siklus II mahasiswa yang dinyatakan berhasil sejumlah 18 mahasiswa (90\%), 2 mahasiswa dinyatakan belum berhasil.

Kondisi mahasiswa sebelum melakukan permainan dapat kita ketahui dengan di adakan tes awal dan mendapatkan data .Setelah dilakukan tindakan siklus I maka prosentase peningkatan keberhasilan mahasiswa 45\%, yakni mahasiswa yang berhasil meningkat sebanyak 9 mahasiswa dengan persentase peningkatan rata-rata 3,3\%. Hasil tindakan siklus I tersebut kemudian dianalisis oleh peneliti dan kolaborator untuk perencanaan tindakan siklus II.Setelah dilakukan tindakan siklus II maka prosentase keberhasilan mahasiswa sebesar 90\%, dengan berhasilnya 18 mahasiswa dengan persentase peningkatan rata-rata $7.5 \%$. Maka dengan demkian terjadi peningkatan dalam permainan swiss ball.

\section{Hasil Penelitian Siklus I}

Siklus pertama kegiatan penelitian dilakukan sesuai dengan perencanaan yakni :

a. Penjelasan peneliti kepada mahasiswa bahwa peneliti akan menggunakan mereka sebagai subjek penelitian dengan situasi duduk di lapangan (2 menit).

b. Mengabsen kehadiran mahasiswa agar peneliti mengetahui jumlah mahasiswa yang dijadikan subjek penelitian (2 menit).

c. Pemberian penjelasan pokok mengenai materi permainan swissball yang akan dilakukan secara singkat (3 menit).

d. Peneliti memerintahkan siswa untuk berdiri dan berbaris 4 saf, setelah itu melakukan pemanasan dan peregangan pada hari pertama, pada hari selanjutnya dilakukan pemanasan dengan permainan (15 menit).

e. memberikan instruksi kepada mahasiswa untuk berbaris berkelompok.

f. Peneliti memberikan materi permainan swiss ball.

g. Setelah itu mahaiswa dicontohkan untuk melakukan permainan swiss ball.

h. Peneliti mengawasi mahasiswa dan melakukan koreksi permainan swiss ball yang dilakukan. 
i. Setelah materi hari itu selesai dilanjutkan pendinginan.

j. Setelah itu dilakukan evaluasi secara keseluruhan.

\section{Hasil Penilaian Siklus II}

Pada siklus 2 kegiatan dilakukan sesuai dengan perencanaan yaitu:

a. Mengabsen kehadiran mahasiswa (2 menit).

b. Pemberian penjelasan pokok mengenai materi permainan swiss ball yang akan dilakukan (3 menit).

c. Peneliti memerintahkan mahasiswa untuk berdiri dan berbaris setelah itu dilakukan pemanasan dengan permainan, dan hari ketujuh dan kedelapan dilakukan pemanasan dengan permainan (15 menit).

d. Setelah itu istirahat selama 5 menit untuk pembenaran gerakan.

e. Peneliti melakukan evaluasi secara menyeluruh.

Proses penelitian yang dilaksanakan pada mahasiswa kop aerobic gymnasticsUniversitas Negeri Jakarta, harus mengacu pada bagaimana menyusun suatu konsep penelitian tindakan. Setiap tahapan siklus yang dilakukan menjadi pedoman dasar peneliti dalam menjalankan siklus-siklus berikutnya secara teratur. Sebuah pengambilan keputusan yang penting dalam menetapkan kondisi awal siswa menjadi sesuatu yang dapat membawa proses penelitian selanjutnya menjadi lebih mudah untuk menentukan konsep pendekatan yang dilakukan. Kondisi awal mahasiswa yang pertama diperhatikan, setelah itu perencanaan proses penelitian, tindakan yang akan dilakukan, observasi kegiatan, dan refleksi yang secara keseluruhan dapat mengantarkan pada penyusunan perencanaan pada siklus berikutnya, setiap perlakuan yang kurang sesuai dapat di kurangi bahkan dihilangkan sehingga menghasilkan tindakan yang lebih baik dan membantu penyusunan program pada langkah yang lebih kecil.

Tahap awal untuk observasi peneliti melihat tingkat kelentukan lower backmahasiswa. Sehingga peneliti dan kolabolator mendapatkan gambaran yang nyata untuk dijadikan bahan pembuatan perencanaan di tahap siklus pertama ini. Proses penelitian diterapkan melalui permainan swiss ball. 


\section{Perencanaan Tindakan}

Tujuan pada penelitian ini yaitu: 1). mahasiswa mengalami peningkatan kelentukan lower backmelalui permainan swiss ball. 2). mahasiswa menjadi lebih bersemangat dalam setiap mengikuti proses penelitian 3). mahasiswa dapat merasa senang saat prosess latihan dengan permainan swiss ball. 4). peneliti mampu memiliki perencanaan yang baik untuk disajikan dalam proses penelitiannya.

\section{Pelaksanaan Tindakan}

Peneliti memiliki perencanaan yang baik untuk dijalankan pada tahap pelaksanaan tindakan. Peneliti dan kolabolator menjalankan proses penelitian dengan permainan swiss ballkepada mahasiswa yang menjadi subjek penelitian. Pada siklus pertama jumlah pertemuan dalam proses penelitian melalui permainan swiss ballyaitu sebanyak 8 (delapan) kali pertemuan. Setiap pertemuan dilaksanakan selama 2 (dua) jam. Proses penelitian dilakukan saat jadwal kegiatan latihan kop aerobic gymnastics.

Peneliti yang bertindak sebagai praktisi mencoba memberikan pembelajaran dengan perencanaan yang telah ditetapkan melalui permainan swiss ball. Ketika proses penelitian berlangsung kolabolator menganalisa baik penampilan, kegiatan mahasiswa dan juga peningkatan-peningkatan yang diperoleh mahasiswa dalam setiap pembelajarannya.

\section{Hasil Observasi}

Pengamatan yang dilakukan kolabolator selama penelitian siklus 1 berlangsung hasilnya sebagai berikut :

1. Mahasiswa yang mengalami peningkatan kelentukan lower back pada siklus I sebanyak $45 \%$.

2. Berdasarkan hasil test kelentukan lower backmahasiswa pada siklus 1 nilai rata-rata peningkatannya adalah $3.3 \%$

3. Hasil mahasswa yang berhasil mengalami peningkatan adalah 9 mahasiswa, dan hasil mahasiswa yang belum mengalami peningktan adalah 11 mahasiswa. 


\section{Analisis Refleksi}

mahasiswa mampu melaksanakan permainan swiss ball yang diterapkan sebagai upaya meningkatkan kelentukan lower back. Hal ini dapat dilihat dari mahasiswa yang memehami perintah yang diberikan.

Dengan demikian dari hasil penilaian siklus II telah terjadi peningkatan dari 45\% menjadi $90 \%$ pada tindakan siklus II, maka dapat disimpulkan bahwa permainan swiss ball dapat meningkatkan kelentukan lower back.

\section{Siklus II}

\section{Perencanaan Tindakan}

Tujuan pada penelitian ini yaitu: 1). mahasiswa mengalami peningkatan kelentukan lower backmelalui permainan swiss ball. 2). mahasiswa menjadi lebih bersemangat dalam setiap mengikuti proses penelitian 3). mahasiswa dapat merasa senang saat prosess latihan dengan permainan swiss ball. 4). peneliti mampu memiliki perencanaan yang baik untuk disajikan dalam proses penelitiannya.

\section{Pelaksanaan Tindakan}

Peneliti memiliki perencanaan yang baik untuk dijalankan pada tahap pelaksanaan tindakan. Peneliti dan kolabolator menjalankan proses penelitian dengan permainan swiss ballkepada mahasiswa yang menjadi subjek penelitian. Pada siklus pertama jumlah pertemuan dalam proses penelitian melalui permainan swiss ballyaitu sebanyak 8 (delapan) kali pertemuan. Setiap pertemuan dilaksanakan selama 2 (dua) jam. Proses penelitian dilakukan saat jadwal kegiatan latihan kop aerobic gymnastics.

Peneliti yang bertindak sebagai praktisi mencoba memberikan pembelajaran dengan perencanaan yang telah ditetapkan melalui permainan swiss ball. Ketika proses penelitian berlangsung kolabolator menganalisa baik penampilan, kegiatan mahasiswa dan juga peningkatan-peningkatan yang diperoleh mahasiswa dalam setiap pembelajaran setelah siklus I.

\section{Hasil Observasi}

Pengamatan yang dilakukan kolabolator selama penelitian siklus II berlangsung hasilnya sebagai berikut : 
1. Mahasiswa yang mengalami peningkatan kelentukan lower back pada siklus I sebanyak $90 \%$.

2. Berdasarkan hasil test kelentukan lower backmahasiswa pada siklus II nilai rata-rata peningkatannya adalah $7.5 \%$

Hasil mahasswa yang berhasil mengalami peningkatan adalah 18 mahasiswa, dan hasil mahasiswa yang belum mengalami peningktan adalah 2 mahasiswa.

\section{KESIMPULAN DAN SARAN}

Berdasarkan dari hasil tes dari 20 mahasiswa data sebagai acuan siklus I dan kemudian hasil tes siklus I sebagai acuan untuk siklus II. Pada siklus I mahasiswa yang dinyatakan berhasil sejumlah 9 mahasiswa (45\%), 11 mahasiswa dinyatakan belum berhasil, dan pada siklus II mahasiswa yang dinyatakan berhasil sejumlah 18 mahasiswa (90\%), 2 mahasiswa dinyatakan belum berhasil dari penjelasan diatas maka dapat disimpulkan bahwa adanya peningkatan setelah diberi tindakan penerapan permainan dengan media swiss ball untuk meningkatkan kelentukan lower back pada mahasiswa kop aerobic gymnastics universitas negeri Jakarta.

\section{DAFTAR PUSTAKA}

Abdoellah, Arma dan Manaji, Agus. 1994. Dasar-Dasar Pendidikan Jasmani. Departemen Pendidikan dan Kebudayaan. Jakarta.

Arikunto, Suharsimi, dkk. 2006. Penelitian Tindakan Kelas. Jakarta: Bumi Aksara

.Sanjaya, Wina. 2007. Strategi Pembelajaran Berorientasi Standar Proses Pendidikan. Jakarta: Kencanal

Supandi. 1992. Strategi Belajar Mengajar Penjaskes. Jakarta: Depdikbud Dirjen Dikti Proyek Pembinaan Tenaga Kependidikan.

Widiastuti,2015. Tes dan Pengukuran Olahraga Jakarta : Rajagrafindo Persada. 